\title{
JOURNAL.RU
}

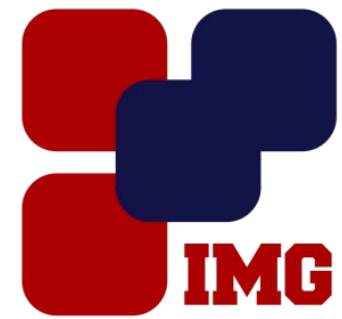
IYANOY Management GROUP

\author{
Ермилов Е.А, Балясников В.А., Олейник В.З., Агровиченко Д.В. \\ Сибирский федеральный университет, Институт нефти и газа, кафедра ТОГСМ \\ Красноярск, Россия
}

doi: 10.18411/lj-31-03-2017-2-04

idsp 000001:lj-31-03-2017-2-04

\section{Оценка влияния процессов окисления и температурной деструкции на противоизносные свойства моторных масел}

\section{Аннотация}

Представлены результаты исследования влияния процессов окисления и температурной деструкции на оптические и противоизносные свойства моторных масел различной базовой основы. Установлено, что процессы температурной деструкции протекают менее интенсивно в начале процесса термостатирования, чем процессы окисления. Причем доминирующее влияние продуктов окисления или температурной деструкции на противоизносные свойства зависит от температуры и базовой основы моторных масел. Предложен обобщенный показатель противоизносных свойств, определяемый отношением средней скорости процессов температурной деструкции к средней скорости процессов окисления.

Ключевые слова: моторное масло,оптическая плотность, показатели противоизносных свойств при окислении и температурной деструкции, обобщенный показатель противоизносных свойств.

При эксплуатации двигателя внутреннего сгорания на поверхностях трения одновременно протекают процессы окисления, температурной деструкции и химические реакции металлов с их продуктами и присадками. Однако доминирующее влияние одного из процессов на противоизносные свойства масел изучены недостаточно. Поэтому целью настоящих исследований являетсяопределение доминирующего влияния продуктов окисления или температурной деструкции на противоизносные свойствамоторных масел различной базовой основы при температурах испытания 170 и $180{ }^{\circ} \mathrm{C}$.

Методика исследования предусматривала применение следующих средств контроля и испытания: прибора для оценки термоокислительной стабильности, прибора для оценки температурной стойкости, фотометра, трехшариковой машины трения, оптического микроскопа «Альтами MET 1М» и электронных весов. Технические характеристики приборов приведены в работах [1-3]. В качестве объектов исследования выбраны моторные масла различной базовой основы, а именно минеральное моторное масло ZicHIFLO 10W-40 SL, частично- 
синтетическое моторное масло CastrolMagnatec 10W-40 RSL/CF и синтетическое моторное масло ALPHA’s 5W-40 SN.

Методика определения термоокислительной стабильности предусматривала два этапа исследования. На первом этапепроба масла массой $100 \pm 0,1 г$ заливались в стеклянный стакан прибора для оценки термоокислительной стабильности и термостатировалосьпоследовательно при температурах 180 и $170^{\circ} \mathrm{C}$ с

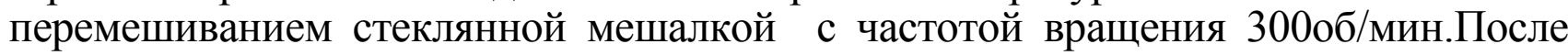
каждых 8-ми часовиспытания отбиралась часть пробы (2г) для прямого фотометрирования и определения оптической плотностиD при толщине фотометрируемого слоя 2 мм

$$
D=\lg \frac{300}{\Pi},
$$

где 300 - задаваемый ток фотометра при пустой кювете, мкА; П - показатель фотометра при фотометрировании термостатированных масел, мкА. 0,5-0,6.

Испытания продолжались до достижения оптической плотности D значений

На втором этапе исследуемые масла испытывались по той же технологии с той лишь разницей, что при достижении оптической плотности $\mathrm{D}$ значений приблизительно равных 0,$1 ; 0,2 ; 0,3 . .0,6$ отбиралась проба окисленного масла 20 г для испытания на машине трения, а проба масла в стакане прибора доливалось до первоначального значения $100 \pm 0,1$.

Оценка противоизносных свойств окисленных масел производилась на трехшариковой машине трения со схемой «шар-цилиндр» [4]. В качестве образцов пары трения использовались шары диаметром 9,5 мм от шарикоподшипников №204 ГОСТ 8338 и обойма роликового подшипника №42416 ГОСТ 8328 диаметром 80 мм, изготовленных из стали ШХ15. Параметры трения составляли: нагрузка $13 \mathrm{H}$; скорость скольжения 0,68 м/с; температура масла в объеме $80^{\circ} \mathrm{C}$; время испытания 1,5 часа. Противоизносные свойства оценивались по среднеарифметическому значению диаметра пятна износа на трех шарах с двух опытов.

Методика определения температурной стойкости предусматривала два этапа исследования. На первом этапе проба масла массой $100 \pm 0,1 \Gamma$ заливались в стеклянный стакан прибора для оценки температурной стойкости и термостатировалось при температурах 180 и $170^{\circ} \mathrm{C}$ без перемешивания при атмосферном давлении с конденсацией паров и отводом конденсата. После каждых 8-ми часов испытания отбиралась часть пробы для прямого фотометрирования и определения оптической плотности $\mathrm{D}$ по формуле 1.Испытания продолжались до достижения оптической плотности D значений равных 0,5-0,6.

На втором этапе производилась оценка влияния продуктов температурной деструкции на противоизносные свойства по вышеописанной технологии.

\section{Результаты исследования и их обсуждения}

На рис. 1 представлены зависимости оптической плотности от времени и температуры испытания исследуемыхмоторных масел различной базовой основы.Согласно данным (рис. 1а-в)процессы старения моторных масел можно разделить на три этапа независимо от базовой основы и температуры испытания. Установлено, что на первом этапе интенсивность процессов окисления и 
температурной деструкции практически одинакова. На втором этапе идет понижение интенсивности процессов температурной деструкции (кривая 1,3 ) над процессами окисления (кривая 2, 4), что объясняется отсутствием перемешивания масла при термостатировании. На третьем этапе испытаний интенсивность процессов температурной деструкции превышает процессы окисления.

Зависимости оптической плотности от времени испытания (рис. 1) имеют изгиб, что свидетельствует об образовании двух видов продуктов старения различной энергоемкости. Регрессионные уравнения зависимостей первых участков $D=f(t)$ для моторных маселпредставлены в таблице 1 .

Таблиича 1

Регрессионные уравнения зависимостей оптической плотности от времени моторных масел (условные обозначения см. на рис. 1)

\begin{tabular}{|c|c|c|c|}
\hline Моторное масло & $\begin{array}{c}\text { Tемпература } \\
\text { испытания, } \\
{ }^{\circ} \mathrm{C} \\
\end{array}$ & Регрессионное уравнение & $\begin{array}{c}\text { Коэффициен } \\
\text { т } \\
\text { корреляции } \\
\end{array}$ \\
\hline \multirow{4}{*}{$\begin{array}{c}\text { Минеральное масло } \\
\text { ZICHIFLO 10w-40 } \\
\text { SL }\end{array}$} & 180 & $D_{1}=3,103 \cdot 10^{-4} \cdot t^{2}-0,004 \cdot t+0,01$ & 0,992 \\
\hline & 180 & $D_{2}=2,497 \cdot 10^{-4} \cdot t^{2}+1,27 \cdot 10^{-4} \cdot t+3,137 \cdot 10^{-4}$ & 0,999 \\
\hline & 170 & $D_{3}=1,068 \cdot 10^{-4} \cdot t^{2}-0,003 \cdot t+0,012$ & 0,976 \\
\hline & 170 & $D_{4}=1,125 \cdot 10^{-4} \cdot t^{2}-0,002 \cdot t+0,009$ & 0,991 \\
\hline \multirow{4}{*}{$\begin{array}{c}\text { Частично- } \\
\text { синтетическое } \\
\text { моторное масло } \\
\text { CastrolMagnatec } \\
\text { 10w-40 SL/CF }\end{array}$} & 180 & $D_{1}=1,7 \cdot 10^{-4} \cdot t^{2}-0,003 \cdot t+0,02$ & 0,971 \\
\hline & 180 & $D_{2}=1,354 \cdot 10^{-4} \cdot t^{2}-0,002 \cdot t+0,014$ & 0,981 \\
\hline & 170 & $D_{3}=5,294 \cdot 10^{-5} \cdot t^{2}-0,002 \cdot t+0,019$ & 0,964 \\
\hline & 170 & $D_{4}=5,569 \cdot 10^{-5} \cdot t^{2}-0,001 \cdot t+0,012$ & 0,977 \\
\hline \multirow{4}{*}{$\begin{array}{c}\text { Синтетическое } \\
\text { моторное масло } \\
\text { ALPHA'S5w-40 SN }\end{array}$} & 180 & $D_{1}=1,648 \cdot 10^{-4} \cdot t^{2}-0,002 \cdot t+0,006$ & 0,998 \\
\hline & 180 & $D_{2}=1,745 \cdot 10^{-4} \cdot t^{2}+8,75 \cdot 10^{-4} \cdot t+8,333 \cdot 10^{-4}$ & 0,999 \\
\hline & 170 & $D_{3}=9,823 \cdot 10^{-5} \cdot t^{2}-0,003 \cdot t+0,02$ & 0,987 \\
\hline & 170 & $D_{4}=6,678 \cdot 10^{-5} \cdot t^{2}-0,001 \cdot t+0,005$ & 0,973 \\
\hline
\end{tabular}

Важным показателем эксплуатационных свойств моторных масел являются их противоизносные свойства, обеспечивающие надежность двигателей. В этой связи важно установить доминирующее влияние на противоизносные свойства продуктов окисления или температурной деструкции. В данной работе предложен показатель противоизносных свойств Ппс, определяемый выражением

$$
\Pi_{\Pi C}=D / h \text {, }
$$

где И - среднеарифметическое значения диаметра пятна износа на трех шарах, MM.

Данный показатель характеризует концентрацию продуктов окисления или температурной деструкции на номинальной площади фрикционного контакта. 


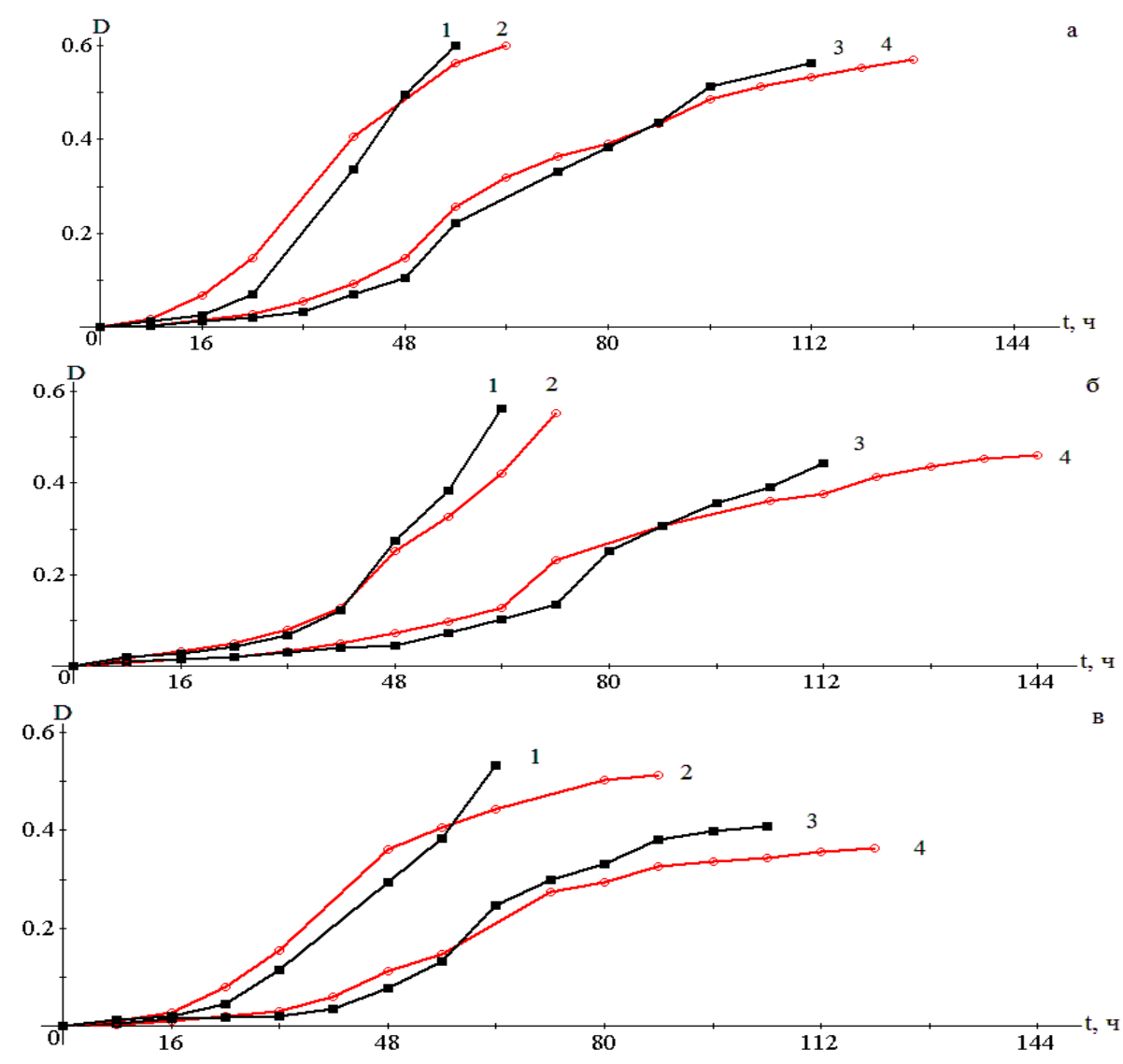

Рис. 1. Зависимости оптической плотности от времени и температуры испытания моторных

масел: 1 - при температурной деструкиии $180{ }^{\circ} \mathrm{C} ; 2$ - при окислении $180{ }^{\circ} \mathrm{C} ; 3-$ температурной деструкиии $170{ }^{\circ} \mathrm{C} ; 4$ - при окислении $170{ }^{\circ} \mathrm{C}$; $a$ - ZicHIFLO 10W-40 SL; б CastrolMagnatec 10W-40 RSL/CF; в - ALPHA's 5W-40 SN

На рис. 2 представлены зависимости критерия противоизносных свойств от оптической плотности.

Установлено, что данные зависимости описываются линейными уравнениями

$$
\Pi_{\Pi C}=\alpha D,
$$

где $\quad \alpha$ - скорость изменения показателя Ппс.

Регрессионные уравнения зависимостей представлены в таблице 2.

Таблийа 2

Результаты регрессионного анализа

\begin{tabular}{|c|c|c|c|c|}
\hline $\begin{array}{l}\text { Моторное } \\
\text { масло }\end{array}$ & $\begin{array}{c}\text { Tемпература } \\
\text { испытания, }{ }^{\circ} \mathrm{C}\end{array}$ & $\begin{array}{c}\text { Процесс } \\
\text { термостатирования }\end{array}$ & $\begin{array}{l}\text { Регрессионное } \\
\text { уравнение }\end{array}$ & $\begin{array}{c}\text { Коэффициент } \\
\text { корреляции }\end{array}$ \\
\hline \multirow{4}{*}{$\begin{array}{c}\text { Минеральное } \\
\text { масло } \\
\text { ZICHIFLO } \\
\text { 10w-40 SL }\end{array}$} & \multirow{2}{*}{ 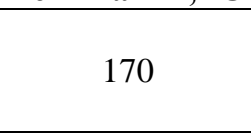 } & Окисление & $\Pi=3,368 \cdot D$ & 0,998 \\
\hline & & $\begin{array}{c}\text { Температурная } \\
\text { деструкция }\end{array}$ & $\Pi=3,628 \cdot D$ & 0,989 \\
\hline & \multirow[b]{2}{*}{180} & Окисление & $\Pi=3,177 \cdot D$ & 0,993 \\
\hline & & $\begin{array}{c}\text { Tемпературная } \\
\text { деструкция }\end{array}$ & $\Pi=3,77 \cdot D$ & 0,999 \\
\hline \multirow{4}{*}{$\begin{array}{c}\text { Частично- } \\
\text { синтетическое } \\
\text { моторное масло } \\
\text { CastrolMagnatec } \\
\text { 10w-40 SL/CF }\end{array}$} & \multirow[b]{2}{*}{170} & Окисление & $\Pi=3,922 \cdot D$ & 0,967 \\
\hline & & $\begin{array}{c}\text { Температурная } \\
\text { деструкция }\end{array}$ & $\Pi=4,377 \cdot D$ & 0,999 \\
\hline & \multirow[b]{2}{*}{180} & Окисление & $\Pi=3,074 \cdot D$ & 0,984 \\
\hline & & $\begin{array}{c}\text { Температурная } \\
\text { деструкция }\end{array}$ & $\Pi=3,728 \cdot D$ & 0,931 \\
\hline
\end{tabular}




\begin{tabular}{|c|c|c|c|c|}
\hline \multirow{2}{*}{$\begin{array}{c}\text { Синтетическое } \\
\text { моторное масло }\end{array}$} & \multirow{2}{*}{\begin{tabular}{c} 
Окиисление \\
ALPHA'S5w-40 \\
\cline { 3 - 5 } SN
\end{tabular}} & $\begin{array}{c}\text { Температурная } \\
\text { деструкция }\end{array}$ & $\Pi=3,461 \cdot D$ & 0,976 \\
\cline { 3 - 5 } & \multirow{2}{*}{180} & Окисление & $\Pi=3,01 \cdot D$ & 0,976 \\
\cline { 3 - 5 } & $\begin{array}{c}\text { Температурная } \\
\text { деструкция }\end{array}$ & $\Pi=3,478 \cdot D$ & 0,989 \\
\hline
\end{tabular}
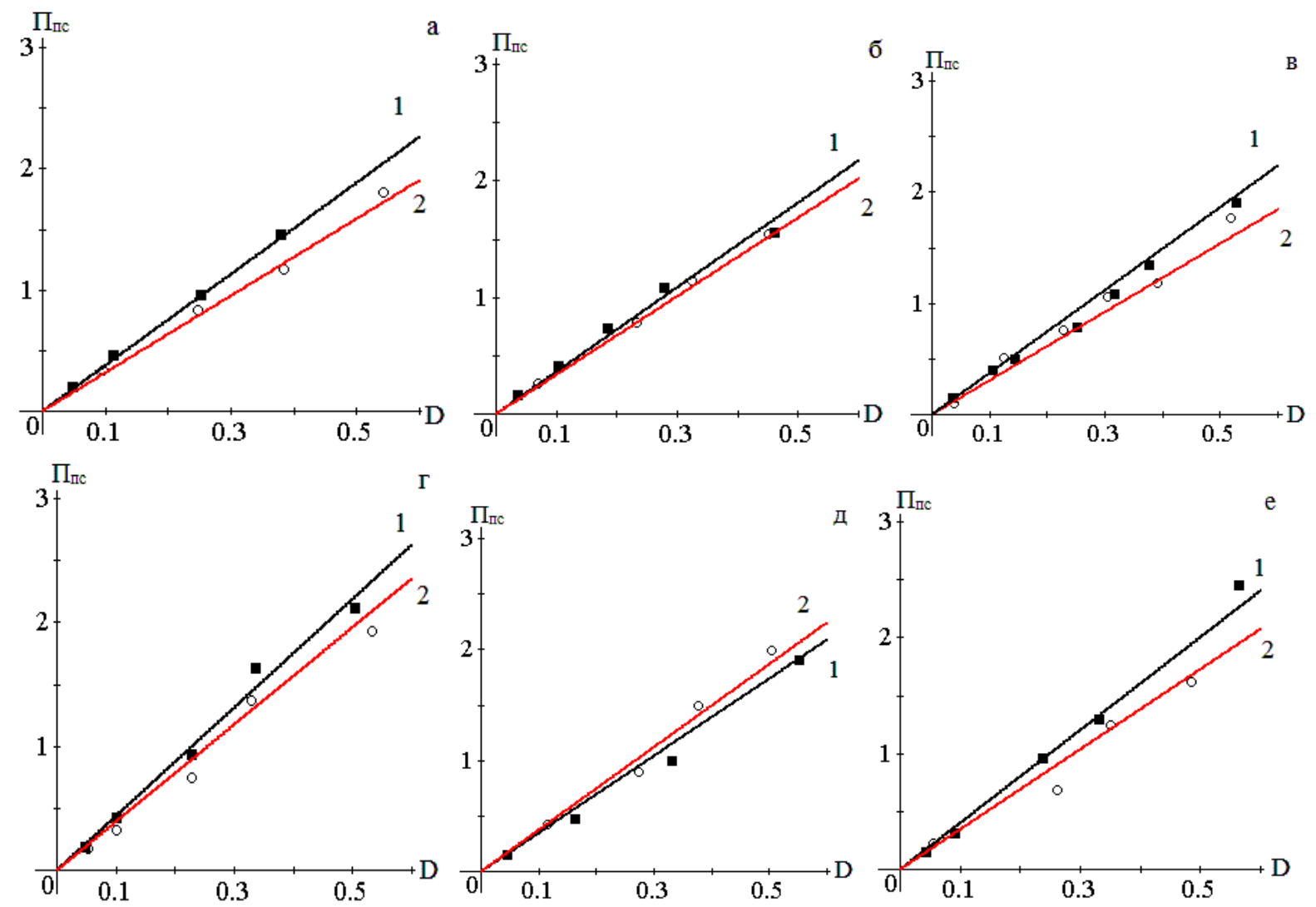

Рис. 2. Зависимости критерия противоизносных свойств от оптической плотности и температуры испытания моторных масел: 1 - при температурной деструкции; 2 - при окислении; $a$-ZicHIFLO 10W-40 SL nри $180^{\circ} \mathrm{C}$; б-ZicHIFLO $10 \mathrm{~W}-40$ SL nри $170{ }^{\circ} \mathrm{C}$; вCastrolMagnatec $10 \mathrm{~W}-40 \mathrm{RSL} / \mathrm{CF}$ npu $180{ }^{\circ} \mathrm{C}$; 2 - CastrolMagnatec $10 \mathrm{~W}-40 \mathrm{RSL} / \mathrm{CF}$ npu $170{ }^{\circ} \mathrm{C}$; $\partial-$ ALPHA's 5W-40 SN npu $180{ }^{\circ} \mathrm{C}$; e-ALPHA's $5 \mathrm{~W}-40$ SN npu $170{ }^{\circ} \mathrm{C}$

Для определения доминирующего влияния процессов окисления или температурной деструкции на противоизносные свойства предложен обобщенный показатель противоизносных свойств (ОППС), определяемый отношением

$$
\text { ОППС }=\frac{\alpha_{T C}}{\alpha_{T O C}},
$$

где аТСи аТОС - параметры, характеризующие средние скорости изменения критериев противоизносных свойств термостатированных и окисленных масел;

Таблица 3

Результаты вычисления обобщенного показателя противоизносных свойств

\begin{tabular}{|l|c|c|}
\hline Моторное масло & Температура испытания, ${ }^{\circ} \mathbf{C}$ & Значение ОППС \\
\hline \multirow{2}{*}{$\begin{array}{l}\text { Минеральное масло ZICHIFLO } \\
\text { 10w-40 SL }\end{array}$} & 170 & 1,076 \\
\cline { 2 - 3 } & 180 & 1,187 \\
\hline
\end{tabular}




\begin{tabular}{|l|c|c|}
\hline Частично-синтетическое & 170 & 1,116 \\
\cline { 2 - 3 } $\begin{array}{l}\text { моторное масло CastrolMagnatec } \\
\text { 10w-40 SL/CF }\end{array}$ & 180 & 1,213 \\
\hline $\begin{array}{l}\text { Синтетическое моторное масло } \\
\text { ALPHA'S5w-40 SN }\end{array}$ & 170 & 1,159 \\
\cline { 2 - 3 } & 180 & 0,931 \\
\hline
\end{tabular}

Согласно данным (таб. 4) с повышением температуры испытания обобщенный показатель противоизносных свойств увеличивается для минерального и частично-синтетического моторных масел, а для синтетического масла он понижается при температуре испытания $180{ }^{\circ} \mathrm{C}$. Кроме того установлено, что продукты температурной деструкции повышают противоизносные свойства масел, кроме синтетического масла при температуре $180{ }^{0} \mathrm{C}$, поэтому эти особенности моторных масел следует учитывать при их выборе для двигателей.

Выводы. На основании проведенных исследований установлено:

1. Процессы температурной деструкции оказывают меньшее влияние на оптические свойства в начале термостатирования моторных масел независимо от базовой основы.

2. Предложен обобщенный показатель противоизносных свойств термостатированных масел, определяемый отношением средней скорости процессов деструкции к средний скорости процессов окисления, характеризующий доминирующие влияния продуктов старения процессов температурной деструкции или окисления на триботехнические характеристики моторных масел.

\section{Литература}

1. Ковальский Б.И. Методы и средства повышения эффективности использования смазочных материалов / Б.И. Ковальский. - Новосибирск: Наука, 2005. - 341 с.

2. Безбородов Ю.Н. Методы контроля и диагностики эксплуатационных свойств смазочных материалов по параметрам термоокислительной стабильности и температурной стойкости: монография / Ю.Н. Безбородов, Б.И. Ковальский, Н.Н. Малышева, А.Н. Сокольников, Е.Г. Мальцева. -Красноярск: СФУ, 2011. - 366 с.

3. Ковальский Б.И. Методы контроля и диагностики эксплуатацион-ных свойств смазочных масел: монография / Б.И. Ковальский, Ю.Н. Безборо-дов, О.Н. Петров, В.Г. Шрам. - Красноярск: СФУ, 2015. - 154 с.

4. Пат. №2428677 Рос. Федерация: МПК G01 N19/02. Устройство для испытания трущихся материалов и масел/ Б.И. Ковальский, Ю.Н. Безбародов, О.Н. Петров, В.И. Тихонов; опубл. 10.09.2011. Бюл.№25. 